\title{
Programmable Networks and Their Social Impact in Developing Countries
}

\author{
Deepa Balagopal \\ Research Scholar \\ Karpagam University \\ Coimbatore,India
}

\author{
X.Agnes Kala Rani, Ph.D \\ Dept. of Computer Science \\ Karpagam University \\ Coimbatore,India
}

\author{
Sandeep Krishnan \\ NIIT Limited \\ Bangalore \\ India
}

\begin{abstract}
Software defined network has been the buzzword among networking professionals since the last few years. SDN promises to simplify network management using its three tiered architecture. Unfortunately, a significant amount of research that is going on in this field is focused on huge enterprise or datacenter networks. The social impact that this technology can bring about especially in developing countries has not been thought of. This paper discusses the societal benefits of using the concept of programmable networks in sectors such as education, healthcare and small scale enterprises. Although various issues faced by the information technology departments in the above mentioned sectors are considered, the focus is mainly on the education sector, especially in the rural areas and the concerns of the technology personnel involved in network management there.
\end{abstract}

\section{General Terms}

SDN, programmable networks, computer networks

\section{Keywords}

Software defined network, SDN, Social impact.

\section{INTRODUCTION}

Any new technology, however revolutionary it may be, will not be meaningful if it is not of any relevance to the society in general. History is replete with instances where technologies that were heralded as revolutionary and launched with much ado were not accepted by consumers. A technology's success is measured by its usefulness and acceptance by the general public.

One such technology that has been accepted and adopted and has become the core of communication is the classical computer network architecture. Ever since its inception and creation of the first internet work, the network has been used to connect different parts of the world together for communication and resource sharing. But, though broad band internet is extensively being used for businesses, online medical consultation as well as virtual classrooms [1], the reachability of these social services is still not sufficient. According to the International Telecommunications Union's report published in October 2013, only about 41.3\% of households across the world have internet access at home and only about $40 \%$ have access to internet in some form [2].

Moreover, the wireless penetration of many regions is much higher than the fixed line penetration mainly due to lower cost and ease of deployment. In particular, the fixed line numbers are low especially in the developing regions due to poor infrastructure, limited purchasing power and low technical knowhow. Not only is the basic communication infrastructure missing in many regions, there is also the problem of not being able to utilize the existing resources due to lack of trained personnel. Network administration has never been considered a simple task due to the plethora of hardware and software that should be installed and managed.

Software defined network, with its simplified approach to managing networks promises to be a boon for enterprises, academic institutions and organizations that are reeling under the pressures of network management and proprietary limitations or elements imposed by equipment vendors. SDN plucks out the control plane intelligence from the proprietary hardware and places it in programmable components known as Controllers. This separation enables a large number of software-driven features in networking, allowing cheaper, but quicker deployment of a network and service infrastructure on demand. It will uniquely enable network operators to move forward from the existing business of managing inflexible infrastructures towards software-enabled network features and service execution environments.

This paper outlines the benefits of SDN and argues that the social impact of SDN will be considerable. In section II a brief introduction to programmable networks is given. In section III the current technology scenario prevalent in the various sections of the society is discussed. Section IV presents the results of a survey conducted among various schools to identify the current state of the networks in those institutions. Section V highlights some of the benefits from programmable networks. Finally in section VI, we conclude our paper.

\section{WHAT ARE PROGRAMMABLE NETWORKS?}

SDN is a networking paradigm with a three tiered architecture - applications at the top, controller in the middle and physical and virtual devices at the bottom [3].

SDN is an attempt to break away from the stranglehold that network hardware manufacturers have on the industry wherein every network device is controlled by a proprietary software within it .Such devices need to be configured individually for it to be a part of the network. This concept, by means of its network virtualization abilities, is also a dream come true for researchers as it allows them to try out new network protocols or applications they develop on a real production network without disrupting the actual network traffic in the process. 


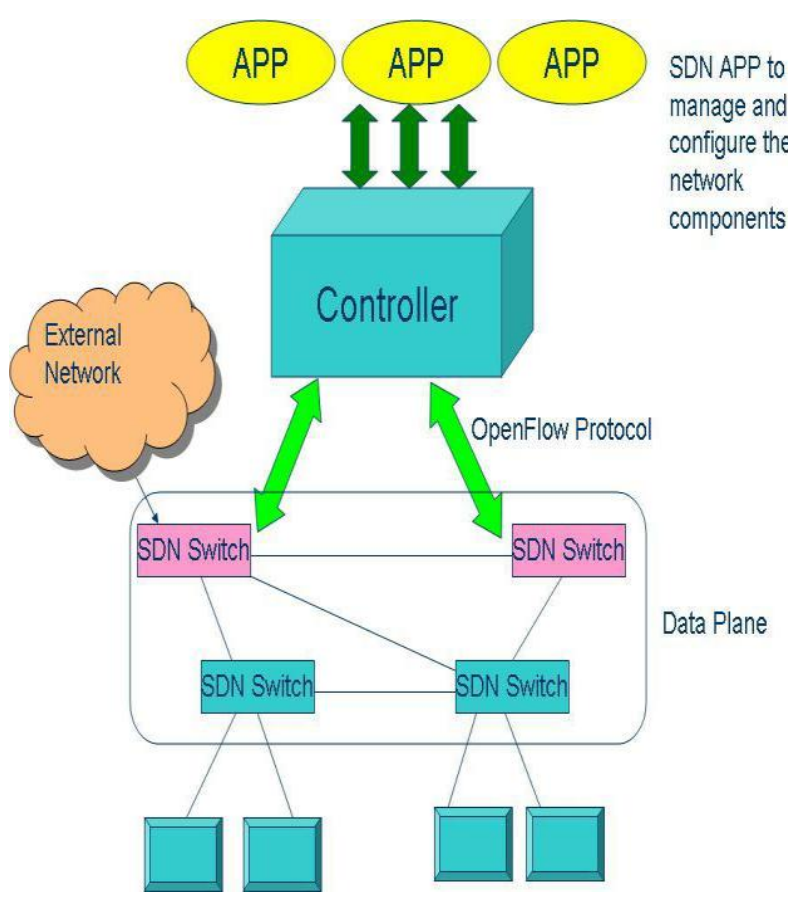

Figure 1 .Software Defined Network

In SDN (see Figure 1), the controller has a global view of the network and manages the state of the network. As we stated earlier, unlike the traditional networks which are made up of proprietary hardware and software and which requires individual attention to be paid to them, the northbound API in SDN allows the network administrators to programmatically control the devices. SDN splits the control plane from the data plane and this enables the network to incorporate newer devices easily [4].

\section{CURRENT SCENARIO}

Why does SDN appear to be a path breaking paradigm? There are several reasons behind this. Hasan et.al talks about how SDN can contribute towards better wireless networks in rural areas [1]. We believe that it is not in wireless networking alone where SDN can play a pivotal role. This section highlights some of the problems faced in certain key areas and how programmable networks can bring about welcome changes to the current situation.

\subsection{Education}

Over the last few years, the field of education has seen many changes. Computers have become part and parcel of education right from the primary level .If there are computers, then there is all possibility that they are connected by means of a network. If there is a network, then the network needs to be administered and this is where the crux of the problem lies.

The use of technology has increased several manifolds in classrooms. This is true especially in developed nations. Educators have brought in mobile devices for using in class rooms. While modern devices may assist in learning, lots of wireless devices demand a good network. As the number of devices increase, so does the complexity of the wireless network. In such cases the school will need more access points professionally configured and managed. With the current network architecture, network problems require highly skilled network administrators - unfortunately they are not easy to come by.
While the use of wireless devices pose a problem in developed regions, institutions which are financially weak and those in the developing regions face a similar shortage of skilled personnel to manage their wired networks. In most schools the teachers themselves double up as technical support even though they have no experience in handling network related issues. This results in wastage of class time. The shortage of skilled network administrators are so severe that in some cases the network is down for days at a time or in the worst case there is no network at all.

The technology issues faced by the schools in South India are discussed in detail in the later section.

\subsection{Healthcare}

With an unprecedented surge in demand for medical care, hospitals require a strong and robust IT system to manage their operations efficiently. In fact today the IT department has become commonplace in most multi specialty hospitals. Most such hospitals heavily rely on IT system and computer networks to keep track of the entire patient treatment cycle.

In such a scenario, the slightest glitch in the IT system could result in a disaster. Moreover, there are laws in many countries that enforce high-level scrutiny of the IT system security and patient data integrity. This makes the job of the IT System/Network manager all the more difficult.

Any network dependant enterprise should have procedures and process in place that facilitate quick fixture of problems in the network. It gets all the more important in the case of a sensitive industry like the healthcare institution. The Mean Time to Repair (MTTR) [5] in hospitals should be minimal since every moment defines the life and death of patients.

Computational technology for effective health care: immediate steps and strategic directions clearly mention the requirement for ubiquitous networking technologies to assist security and searching [6].

\subsection{Small scale enterprises}

One of the most important tasks for a network administrator in a business is to maintain the network connectivity within the organization. Keeping the downtime minimum ensures the continuity in productivity. This task is difficult since in most cases the network infrastructure would be made up of hardware from numerous vendors.

Moreover, in the conventional architecture, network configuration is tightly coupled to hardware. This consumes a lot of time in performing repetitive configurations. Again, no centralized control exists for keeping track of configuration changes, updates and other mission critical steps necessary to meet the compliance regulations in vogue for businesses.

Apart from the configuration complexities, security measures such as intrusion detection monitoring, firewalls and patches also need to be routinely carried out. These by any means are not tasks that can be taken lightly.

\section{THE STATE OF TECHNOLOGY IN THE K12 SECTOR IN SOUTH INDIA}

About a decade back, Brewer et.al ,in their article titled 'The case for technology in developing nations' stressed on the need for a cost effective network infrastructure in rural regions[7].There has also been publications on the effectiveness of shared computing model in developing regions [8]. Unfortunately since then, not counting those carried out in the field of wireless networks, very few studies 
have been conducted on the existence of hardcore networking technology, awareness about it and its usage in developing nations. Since the focus was on the social impact of SDN, the authors wanted to get some data on how the networking technology is being put to use in the service sectors of the society .With this in mind, the authors zeroed in on the education sector. This sector was chosen mainly for the reason that information technology is an integral part of every curriculum and is taught in schools from class 1 onwards.

As part of the study, a survey was conducted amongst K12 schools in South India, primarily in the states of Karnataka, Kerala and some parts of TamilNadu to determine the infrastructure availability, awareness and skill level among the faculty and network administrators. The main objective of the survey was to find if the concerned institution had a computer network in place, how the network being managed and what was were the difficulties faced to maintain the same. The institutions which had computers, but no computer network were asked to mention the reasons for not having one. The results of the survey are described below.

\subsection{Number of schools surveyed}

During the course of the study, a total of 100 schools were approached in four different states. Care was taken to ensure that the sample had a good mix of schools located in rural and urban localities. The following table lists the state wise breakup of the number of schools surveyed.

Table 1.State wise break up of schools

\begin{tabular}{|c|c|c|c|}
\hline & \multicolumn{3}{|c|}{ No. of schools surveyed } \\
\hline $\begin{array}{c}\text { Grand } \\
\text { Total }\end{array}$ & Karnataka & Kerala & Tamil Nadu \\
\hline 100 & 61 & 28 & 11 \\
\hline
\end{tabular}

The data was collected from 10 different districts of Karnataka, 11 districts of Kerala and 5 districts of Tamil Nadu. These schools belonged to three strata - premier, average and under privileged.

\subsection{Extent of networked schools}

One of the first questions put forth to the school representative was whether the systems in their institution were connected by a network. Most of the schools answered in the affirmative. As can be seen from Table 2, out of 100 schools, 67 said that they were networked and 33 said that they were not.

Table 2.No. of schools with computer network

\begin{tabular}{|c|c|c|}
\hline & \multicolumn{2}{|c|}{$\begin{array}{c}\text { No. of schools with } \\
\text { computer network }\end{array}$} \\
\hline Grand Total & Yes & No \\
\hline 100 & 67 & 33 \\
\hline
\end{tabular}

Table 3.Statewise distribution of networked schools

\begin{tabular}{|c|c|c|c|c|c|}
\hline \multicolumn{3}{|c|}{ State wise distribution of schools with computer network } \\
\hline \multicolumn{2}{|c|}{ Karnataka } & \multicolumn{2}{|c|}{ Kerala } & \multicolumn{2}{c|}{ Tamil Nadu } \\
\hline Yes & No & Yes & No & Yes & No \\
\hline 37 & 24 & 23 & 5 & 6 & 5 \\
\hline
\end{tabular}

The above replies were also analyzed based on the state to which the schools belonged to and it was found that while the average and under privileged schools were not using computer network due to financial constraints and lack of awareness, surprisingly, some of the premier schools with a fee structure of 50,000 per year and possessing approximately 50 to 90 computers in the labs too did not opt for a networked infrastructure.

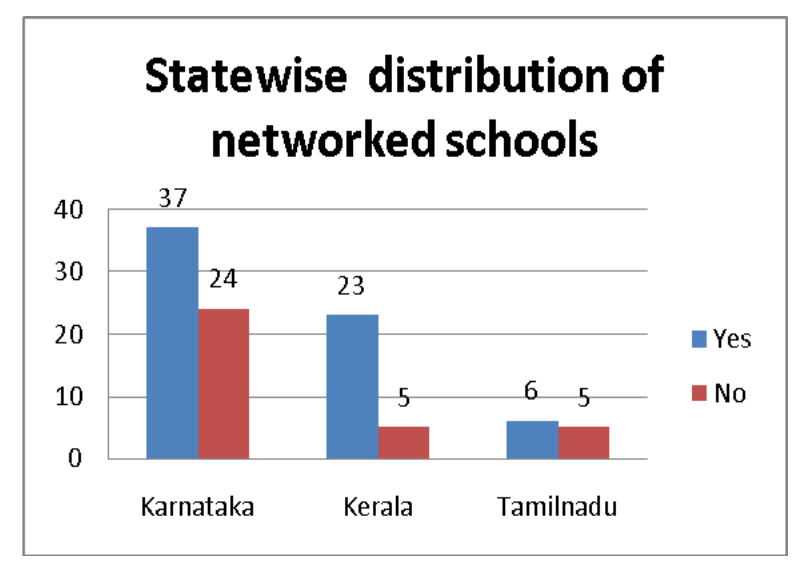

Figure 2. Count of schools covered per state

In general, it was observed that out of the 100 schools in the sample, there were 92 schools with more than 20 computers split across the lab and administrative sections and out of these 25 schools had not gone for networking their computers. The reasons stated predominantly varied between lack of funds and not identifying the need for a network.

\subsection{Availability of network administrator}

As part of the study, the schools were also asked if they had an in-house network administrator to maintain the hardware and software systems that make up the computer network. While analyzing the answers to this question, it was understood that most schools considered network administration and hardware maintenance as one and the same. This is an accepted trend in most organizations due to various factors such as size and the economics involved [9]. Hence all those schools who either said that they have network administrator or hardware engineer were clubbed together. Table 4 shows how many of the schools have network administrator.

Table 4.Schools with network administrator

\begin{tabular}{|c|c|c|}
\hline & \multicolumn{2}{|c|}{$\begin{array}{c}\text { No. of schools with } \\
\text { Network Administrator }\end{array}$} \\
\hline Grand Total & Yes & No \\
\hline 100 & 39 & 61 \\
\hline
\end{tabular}

The above number was arrived after sifting through the data and removing all those schools who considered computer faculty as the network administrator. It was surprising to observe many of the schools in spite of having more than 30 systems did not have a network administrator or a hardware engineer. Most of them relied on the computer faculty to solve the system related problems, irrespective of whether it is related to hardware, software or network. The hardware engineer would be called in only if the faculty was unable to handle the issue. 


\subsection{Problems faced by schools}

The schools were also asked to list out the problems they were facing with the network and in general with the systems in their organization. Most of the schools had multiple issues irrespective of whether there was a network or not. Figure 3 depicts the problems being faced by schools in managing the information technology infrastructure.

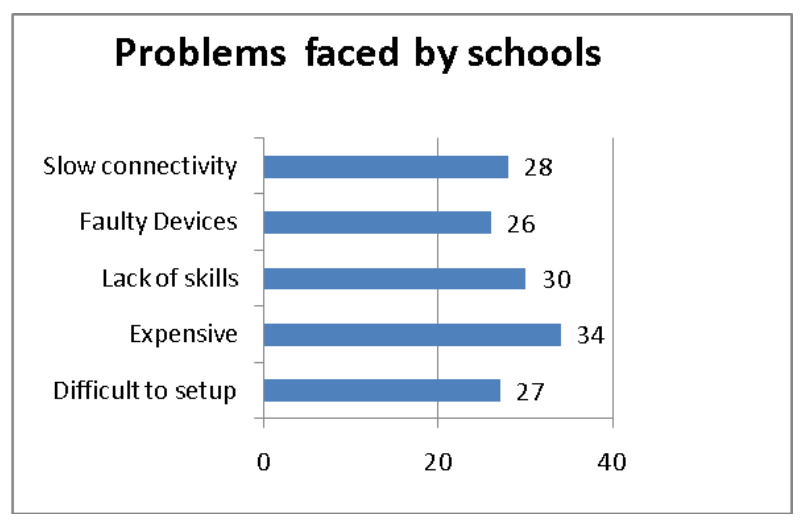

Figure 3.Problems faced by schools

\subsection{Awareness of current technology and SDN}

Except for some top level schools, most of the schools were seen to be using outdated software and devices. Long forgotten operating systems such as Windows 2000 were still being used. The technical know-how of the administrative staff was found to be bare minimum. Unfortunately in some cases, the authors had to explain to the faculty the concept of computer network before collecting the answers to the survey questions.

When the schools were asked if they had heard about the technology of SDN, only 26 out of 100 schools answered positively. Not surprisingly, 25 of these schools were those who had a certified network administrator. The rest of the schools, even though they had not heard of SDN were receptive to the idea of a network being managed by software.

\section{HOW CAN SDN HELP?}

The sentiments of the networking industry in general can be gauged from the results of the survey Gigaom Research ran in December 2013 amongst 600 operators in North America [10]. Over $60 \%$ cited network management \& operating expenses as major issues that need to be taken care of.

Given the numerous networking challenges that various service sectors face, we now list the possible benefits that programmable networks can provide for better and improved network management.

\section{Better Security}

As the network grows in terms of devices and users, so does the security challenges associated with it. A typical network comes with a lot of manual work for identifying and eliminating network threats. The centralized control in SDN allows a proactive management of threats and decreases the time spent on security problems.

\section{Flexibility and cost-effectiveness}

The decoupling of the control plane and data plane in SDN makes it possible to create a flexible hardware implementation [11]. Network administrators can correct the network issues programmatically rather than reconfigure a whole lot of hardware networking devices, and that can translate to lower costs and also save a lot of time. Moreover, different types of third party applications can be run on this hardware without the need for any $\mathrm{h} / \mathrm{w}$ specific configuration.

SDN also supports network virtualization which makes it possible to allocate the underlying physical network resources to a virtual network as required by the current needs of the establishment .It makes networks dynamic, allowing organizations to rapidly scale services and functions. For instance, governments could have multiple independent virtual networks for various public services like police department, fire services, universities and healthcare over the physical networks [12]. This means that network can a) be reconfigured to meet the varying needs of each service b) services can be segregated.

Moreover, since the network intelligence is placed within a controller program, the network traffic can be controlled without having to deal with the hardware devices. Hence extensive physical expertise for managing the network is not required as is the case today. This can considerably reduce the operating expenses which would be beneficial to organizations with limited funds.

\section{CONCLUSION}

Since the technology of SDN is still in its growing phase, it may appear to be too early to predict its social impact on the various service sectors. Our study shows that most sectors, especially the K12 education sector has not benefited from the classic networking technology. Although many institutions have adopted it, they have neither been able to utilize it to its full potential nor have been able to keep up with the reforms happening in the field. The poor standard of technology in the $\mathrm{K} 12$ sector is especially of concern since this is where the foundation of a future generation is laid. From our study it was found that this is because of the complexity and expenses involved in bringing about the changes to the available networked infrastructure for which capital has already been spent. The simplicity and flexibility promised by SDN in terms of network management and the reduced costs of setting up a network could go a long way in improving the usage and awareness of technology in the educational institutions.

\section{ACKNOWLEDGMENT}

The survey conducted in this research was supported by NIIT Limited, India. The author would like to thank all those involved in conducting this study and Olatunde Awobuluyi for his valuable inputs while writing this paper.

\section{REFERENCES}

[1] Hasan, Shaddi, Yahel Ben-David, Colin Scott, Eric Brewer, and Scott Shenker. "Enhancing rural connectivity with software defined networks." In Proceedings of the 3rd ACM Symposium on Computing for Development, p. 49. ACM, 2013.

[2] International Telecommunication Union. "Measuring the Information Society 2013," [Online] Available: http://www.itu.int/ITU-D/ict/statistics/.

[3] Kirkpatrick, K. "Software defined networking," Communications of the ACM Vol 56,No. 9 ,September 2013,pp. 16- 19.

[4] SDN Architecture Overview. [Online]Available: https://www.opennetworking.org/images/stories/downloa $\mathrm{ds} / \mathrm{sdn}$-resources/technical-reports/SDN-architectureoverview-1.0.pdf (2013) 
[5] White, M.C. "Network Design and Management." Chapter 13.In Data Communications and Computer Networks: A Business User's Approach. 6th ed. Cengage Learning, 2010.

[6] National Research Council (US) Committee on Engaging the Computer Science Research Community in Health Care Informatics; Stead WW, Lin HS, editors. "Computational Technology for Effective Health Care: Immediate Steps and Strategic Directions." Washington (DC): National Academies Press (US); 2009. Committee on Engaging the Computer Science Research Community in Health Care Informatics. Available: http://www.ncbi.nlm.nih.gov/books/NBK20629/

[7] Brewer, Eric, Michael Demmer, Bowei Du, Melissa Ho, Matthew Kam, Sergiu Nedevschi, Joyojeet Pal, Rabin Patra, Sonesh Surana, and Kevin Fall. "The case for technology in developing regions." Computer 38, no. 6 (2005): 25-38.

[8] Patra, Rabin, Joyojeet Pal, Sergiu Nedevschi, Madelaine Plauche, and Udai Pawar. "Usage models of classroom computing in developing regions." In Information and Communication Technologies and Development, 2007.
ICTD 2007. International Conference on, pp. 1-10. IEEE, 2007.

[9] http://en.wikipedia.org/wiki/Network_administrator (accessed June 29,2014)

[10] Leary,Mark. "SDN, NFV and Open source: the operator's

view."research.gigaom.com.http://research.gigaom.com/r eport/sdn-nfv-and-open-source-the-operators-view/ (accessed March 25, 2014).

[11] Bosshart, Pat, Glen Gibb, Hun-Seok Kim, George Varghese, Nick McKeown, Martin Izzard, Fernando Mujica, and Mark Horowitz. "Forwarding metamorphosis: Fast programmable match-action processing in hardware for SDN." In Proceedings of the ACM SIGCOMM 2013 conference on SIGCOMM, pp. 99-110. ACM, 2013.

[12] Basu,Medha."Software-defined networking to meet changing public demands."Futuregov.asia. http://www.futuregov.asia/articles/2014/jan/21/softwaredefined-networking-meet-changing-public-d/ (accessed March 25, 2014) 